\title{
Morphology engineering - Osmolality and its effect on Aspergillus niger morphology and productivity
}

Thomas Wucherpfennig, Timo Hestler and Rainer Krull

\begin{abstract}
Background: The filamentous fungus Aspergillus niger is a widely used strain in a broad range of industrial processes from food to pharmaceutical industry. One of the most intriguing and often uncontrollable characteristics of this filamentous organism is its complex morphology, ranging from dense spherical pellets to viscous mycelia depending on culture conditions. Optimal productivity correlates strongly with a specific morphological form, thus making high demands on process control.

Results: In about 50 2L stirred tank cultivations the influence of osmolality on A. niger morphology and productivity was investigated. The specific productivity of fructofuranosidase producing strain A. niger SKAn 1015 could be increased notably from 0.5 to $9 \mathrm{U} \mathrm{mg}^{-1} \mathrm{~h}^{-1}$ around eighteen fold, by increasing the culture broth osmolality by addition of sodium chloride. The specific productivity of glucoamylase producing strain $A$. niger AB1.13, could be elevated using the same procedure. An optimal producing osmolality was shown to exist well over the standard osmolality at about $3.2 \mathrm{osmol} \mathrm{kg}^{-1}$ depending on the strain. Fungal morphology of all cultivations was examined by microscope and characterized by digital image analysis. Particle shape parameters were combined to a dimensionless Morphology number, which enabled a comprehensive characterization of fungal morphology correlating closely with productivity. A novel method for determination of germination time in submerged cultivations by laser diffraction, introduced in this study, revealed a decelerated germination process with increasing osmolality.

Conclusions: Through the introduction of the versatile Morphology number, this study provides the means for a desirable characterization of fungal morphology and demonstrates its relation to productivity. Furthermore, osmolality as a fairly new parameter in process engineering is introduced and found to affect fungal morphology and productivity. Osmolality might provide an auspicious and reliable approach to increase the productivity in industrial processes. Because of the predictable behavior fungal morphology showed in dependence of osmolality, a customization of morphology for process needs seems feasible.
\end{abstract}

Keywords: Aspergillus niger, fungal morphology, productivity, osmolality, fructofuranosidase, glucoamylase, image analysis, pellets, germination time

\section{Background}

The filamentous fungus Aspergillus niger is a widely used strain in a broad range of industrial processes from food to pharmaceutical industry [1-7]. One of the most prominent characteristics of this filamentous organism is its complex morphology. In submerged cultivation two distinct growth forms can be observed, the mycelial and the pelleted form [8-10]. A study of fungal morphology is

\footnotetext{
* Correspondence: r.krull@tu-braunschweig.de

Institute of Biochemical Engineering, Technische Universität Braunschweig, Gaußstraße 17, 38106 Braunschweig, Germany
}

highly recommended for process optimization [11]. Depending on the expressed product the optimal morphology for a given bioprocess varies [12], optimal productivity, however, correlates strongly with a specific morphological form [13-15]. This growth form not only determines the productivity of a bioprocess, but also has a significant impact on mixing and mass transfer within the bioreactor. To ensure high protein secretion and at the same time a low viscosity of the cultivation broth, it is desired by the industry to tailor-make the morphology of filamentous fungi [16]. Various process parameters and ingredients have been described in literature to

\section{(Ciomed Central}


influence fungal morphology [17-21], an extensive list can be found in Wucherpfennig et al. (2010) [22].

There is an abundance of literature on the effects of metal and other ions on fungal growth and metabolite production [3]. Only very few studies are devoted to the effect of so-called inert salts like sodium chloride or potassium chloride which are supposed to have no effect on metabolism. Allaway and Jennings (1970), for example, report a decrease of growth of the marine fungus Dendryphiella salina in the presence of $200 \mathrm{mM}$ sodium and potassium chloride $[23,24]$. Bobowicz-Lassociska et. al. (1995) were able to increase protein secretion of washed and filtered $A$. niger mycelia by addition of $\mathrm{KCl}$. An enhanced membrane permeability due osmotic pressure was argued to be responsible for the significant increase in soluble protein [25]. In addition, Fiedurek (1997) was able to increase the activity of $A$. niger expressed glucose oxidase 2.1 fold by adding $1.2 \mathrm{M} \mathrm{NaCl}$ to centrifuged mycelia, thus administering an osmotic shock to the fungus. It was further speculated that osmotic potential should be considered as a possible regulating factor in studies on the synthesis and secretion of microbial enzymes [26]. In both studies fungal mycelia were administered to an osmotic shock. No work was done on the effect of osmolality of cultivation medium on fungal growth and productivity. In the field of mammalian cell cultivation, however, an increase in osmolality is a well-known tool to increase specific productivity and sometimes final product titer [27-31]. Osmolality is generally dependent on the medium composition and changes during cultivation through accumulation of metabolic products and $\mathrm{pH}$ control, through addition of acid or base. Most culture media have an osmolality between 0.28 and $0.32 \mathrm{osmol} \mathrm{kg}^{-1}$.

In the present work, the influence of osmolality on morphology and productivity of two strains of $A$. niger was studied. For holistic morphologic description of fungal morphology a dimensionless Morphology number was introduced. The macroscopic morphology was successfully correlated with enzyme productivity in both strains. The expressed fructofuranosidase (EC 3.2.1.26) catalyzes the conversion of the disaccharides like sucrose into fructooligosaccharides. The market for fructooligosaccharides has great potential, due to their interesting functional properties. Their application ranges from new prebiotic products commercially available to the pharmaceutical or the diagnostic sector [32-34]. Glucoamylase (GA, EC 3.2.1.3) is a homologous protein used for hydrolysis of starch in many industrial applications [35].

\section{Results and discussion}

\section{Effect of osmolality on A. niger productivity}

Osmolality notably affected growth rate and conidia aggregation of $A$. niger. Fructofuranosidase and glucoamylase production in $A$. niger was, in about $502 \mathrm{~L}$ cultivations, shown to be sensitive to osmolality (Figure 1 and 2). For the fructofuranosidase producing strain A. niger SKAn 1015 , increasing osmolality within the bioreactor from the standard 0.4 to $4.9 \mathrm{osmol} \mathrm{kg}^{-1}$ led to a considerable decline in dry cell weight from around 4 to $0.2 \mathrm{~g} \mathrm{~L}^{-1}$, respectively. Meanwhile the specific productivity, as defined in Methods, increased remarkably from 0.5 to $9 \mathrm{U} \mathrm{mg}^{-1} \mathrm{~h}^{-1}$ around eighteen fold (Figure 1A). This distinct increase is

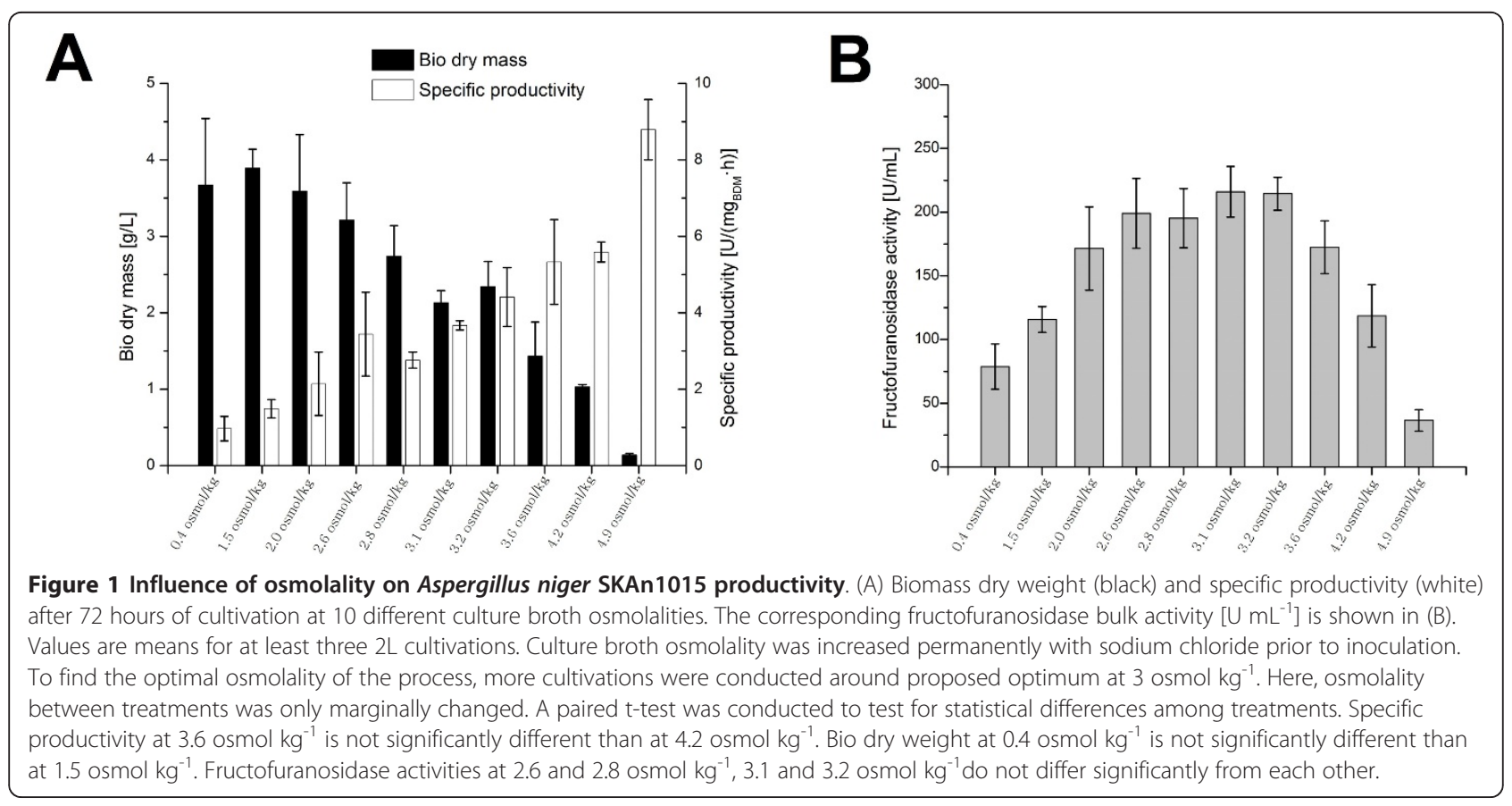


somewhat put into perspective by considering the volumetric fructofuranosidase activity in bulk as illustrated in Figure 1B. Up to an osmolality of $2.6 \mathrm{osmol} \mathrm{kg}^{-1}$ the fructofuranosidase bulk activity is shown to increase about two and a half times. To find the optimal osmolality for the process, a considerable amount of cultivations was conducted at similar osmolality. Optimal fructofuranosidase activity of $220 \mathrm{U} \mathrm{mL}^{-1}$ was detected at an osmolality of about 3 osmol kg-1. Thus osmolality between cultivations around 3 osmol kg-1 was varied only marginally (Figure 1). In contrast, an osmotic pressure of more than 3.2 osmol kg-1 reduces the fructofuranosidase activity per milliliter. An addition of $1.5 \mathrm{M}$ sodium chloride to the cultivation medium is shown to be beneficial for fructofuranosidase production.

To check whether increasing osmolality interfered with fructofuranosidase assay, culture supernatant from a standard cultivation with $0.4 \mathrm{osmol} \mathrm{kg}^{-1}$ was sterile filtered. In one half, the osmolality was increased up to $2.4 \mathrm{osmol} \mathrm{kg}^{-1}$ through addition of sodium chloride, the other half was left untreated. Subsequently, the fructofuranosidase assay was performed for both samples. The samples were with $54.6 \pm 0.4 \mathrm{U} \mathrm{mL}^{-1}$ were found to have the same fructofuranosidase activity ruling out the influence of osmolality on the fructofuranosidase assay used in this study. Moreover, no significant impact on dissolved oxygen within the bioreactor could be detected $\left(\mathrm{pO}_{2}\right.$-probe, Mettler-Toledo) while increasing the osmolality of the cultivation broth, suggesting that osmolality had no effect on the availability of dissolved oxygen for microorganisms.
Another strain of $A$. niger, the GA producing strain AB1.13 was used to test reproducibility of the beneficial effect of osmolality for enzyme production. Although both strains originate from the same clone, their cultivation performance and handling is considerably different, thus making it reasonable to compare, how both strains are affected by osmolality. Glucoamylase in A. niger AB1.13 is in contrast to fructofuranosidase in A. niger SKAn 1015 not overexpressed, thus lower activities in general were expected. The cultivation medium for this strain had an osmolality of only $0.2 \mathrm{osmol} \mathrm{kg}{ }^{-1}$. A. niger AB1.13 was observed to be more sensitive towards osmotic pressure, than A. niger SKAn 1015. Here an osmolality of only 2.4 led to a perfectly mycelial growth. Up to 1.8 osmol $/ \mathrm{kg}$, however, growth of both strains was comparable. The increased osmolality led to a twofold decreased biomass and around a factor five increased specific productivity in this strain (Figure 2A). The GA activity within the bulk sample correspondingly increased about 4.5 times, while the osmolality was raised from 0.2 to

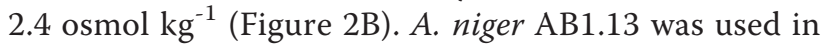
this study as backup to substantiate the findings made with $A$. niger SKAn 1015. Because of this and since A. niger SKAn 1015 is in the focus of this study a total number of only 10 cultivations with the $\mathrm{AB} 1.13$ strain were carried out causing a higher standard deviation in Figures 2A and Figure 2B compared with the 40 SKAn1015 cultivations. Osmolality was found to have an inhibiting effect on growth both strains, while the productivity of the biomass was considerably increased. Maximal growth rate $\left(\mu_{\max }\right)$ was negatively affected by

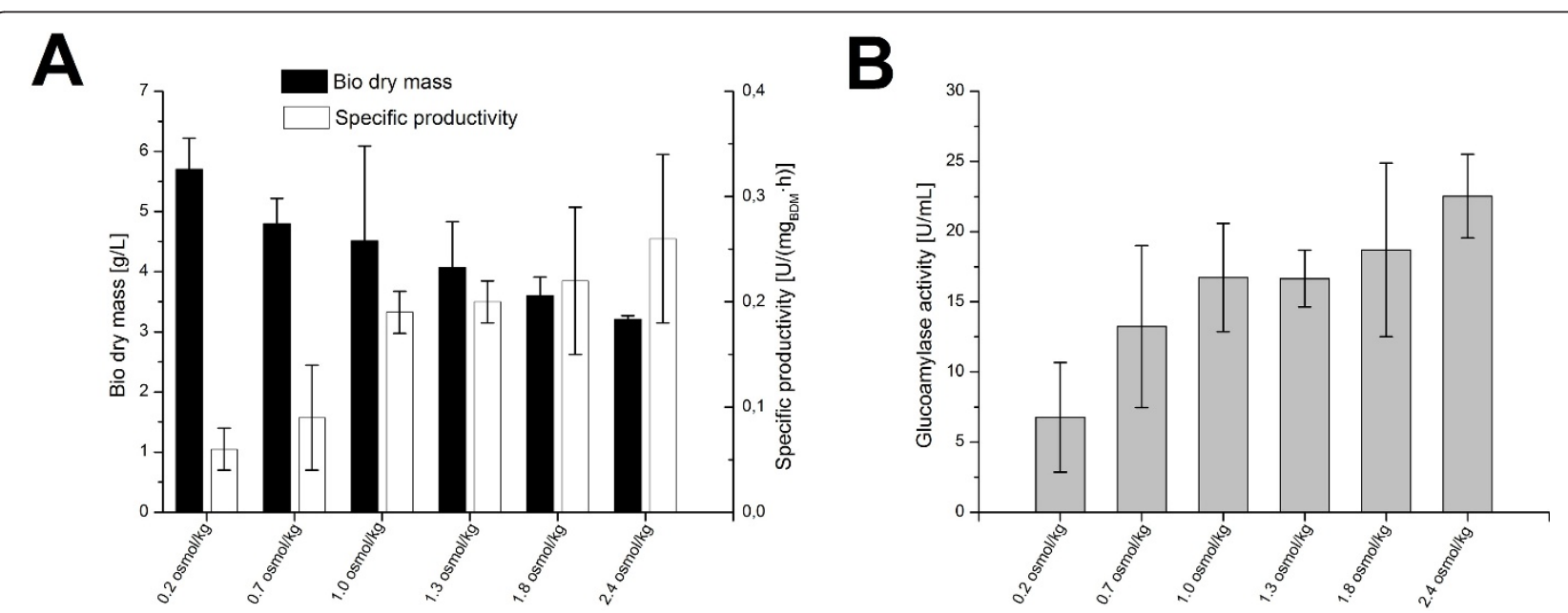

Figure 2 Influence of osmolality on Aspergillus niger AB1.13 productivity. (A) Biomass dry weight (black) and specific productivity (white) after 72 hours of cultivation at 6 different culture broth osmolalities. The corresponding glucoamylase bulk activity $\left[U \mathrm{~mL}^{-1}\right]$ is shown in (B). Values are means for at least two $2 \mathrm{~L}$ cultivations. Culture broth osmolality was increased permanently with sodium chloride prior to inoculation. A paired t-test was conducted to test for statistical differences among cultivations with varying osmolality. Bio dry weight was not found to differ significantly between 0.7 and $1.0 \mathrm{osmol} \mathrm{kg}{ }^{-1}$. Glucoamylase bulk activity at osmolality of 0.7 and $1.0 \mathrm{osmol} \mathrm{kg}{ }^{-1}, 1.3$ and $1.8 \mathrm{osmol} \mathrm{kg}^{-1}$ showed no significant difference. 
osmotic pressure within the culture broth, and decreased from $0.16 \mathrm{~h}^{-1}$ at standard osmolality to $0.02 \mathrm{~h}^{-1}$ at 4.5 osmol kg-1. Bulk activity of expressed enzymes only increased up to optimal osmolality, whereas the positive effect of increased productivity outweighed the decrease in biomass.

According to previous works productivity could be incremented after an administration of an osmotic shock to the culture $[25,26]$. In this study, an osmotic shock significantly increased enzyme activity only when administered to culture broth of standard osmolality (Figure 3). In order to investigate the effect of an osmotic shock on fructofuranosidase activity, one $A$. niger SKAn 1015 cultivation at standard osmolality of $0.4 \mathrm{osmol} \mathrm{kg}$ and a cultivation at an elevated osmolality of $2.8 \mathrm{osmol} \mathrm{kg}^{-1}$ were conducted. After 72 hours of cultivation biomass was collected from each cultivation. Half of the sample was subjected to an osmotic shock with sodium chloride, the other half left untreated. Both samples were subsequently incubated in shake flasks at $37^{\circ} \mathrm{C}$, at $120 \mathrm{~min}^{-1}$ for one hour, before measuring the fructofuranosidase activity. Experiments were conducted in triplicate. For sample cultivated initially at $0.4 \mathrm{osmol} \mathrm{\textrm {kg } ^ { - 1 }}$, fructofuranosidase activity was increased about $10.8 \%$, from 88,8 to $98,4 \mathrm{U}$ $\mathrm{mL}^{-1}$, due to an instantaneous increase in osmolality to 2.8 osmol $\mathrm{kg}^{-1}$. When the same sample was administered to an osmolality of $4.5 \mathrm{osmol} \mathrm{kg}{ }^{-1}$, fructofuranosidase activity increased even further to $103.4 \mathrm{U} \mathrm{mL}^{-1}$ (Figure 3A). No significant increase in fructofuranosidase activity could be assessed for $A$. niger SKAn 1015 sample cultivated at 2.8 osmol kg-1 and shocked to 4.5 osmol kg ${ }^{-1}$. The GA producing strain $A$. niger AB1.13 was treated likewise. In this case, GA activity could be increased by about $50 \%$ (Figure $3 \mathrm{~B})$, through rapid elevation of culture broth osmolality from 0.2 to $2.5 \mathrm{osmol} \mathrm{kg}$. An osmotic shock from initially 1.3 to 2.5 osmol kg-1, however, did not affect GA activity (Figure 3B). For both strains an osmotic shock was only beneficial for enzyme activity, when the fungal biomass cultivated at standard osmolality and therewith not adapted to a highly osmotic environment.

Besides sodium chloride, other inert salts were tested for increasing the osmotic pressure of the medium. Only potassium chloride yielded comparable results (data not shown). Other salts like lithium chloride, lithium bromide, caesium chloride, potassium iodide and sodium iodide repressed growth of $A$. niger.

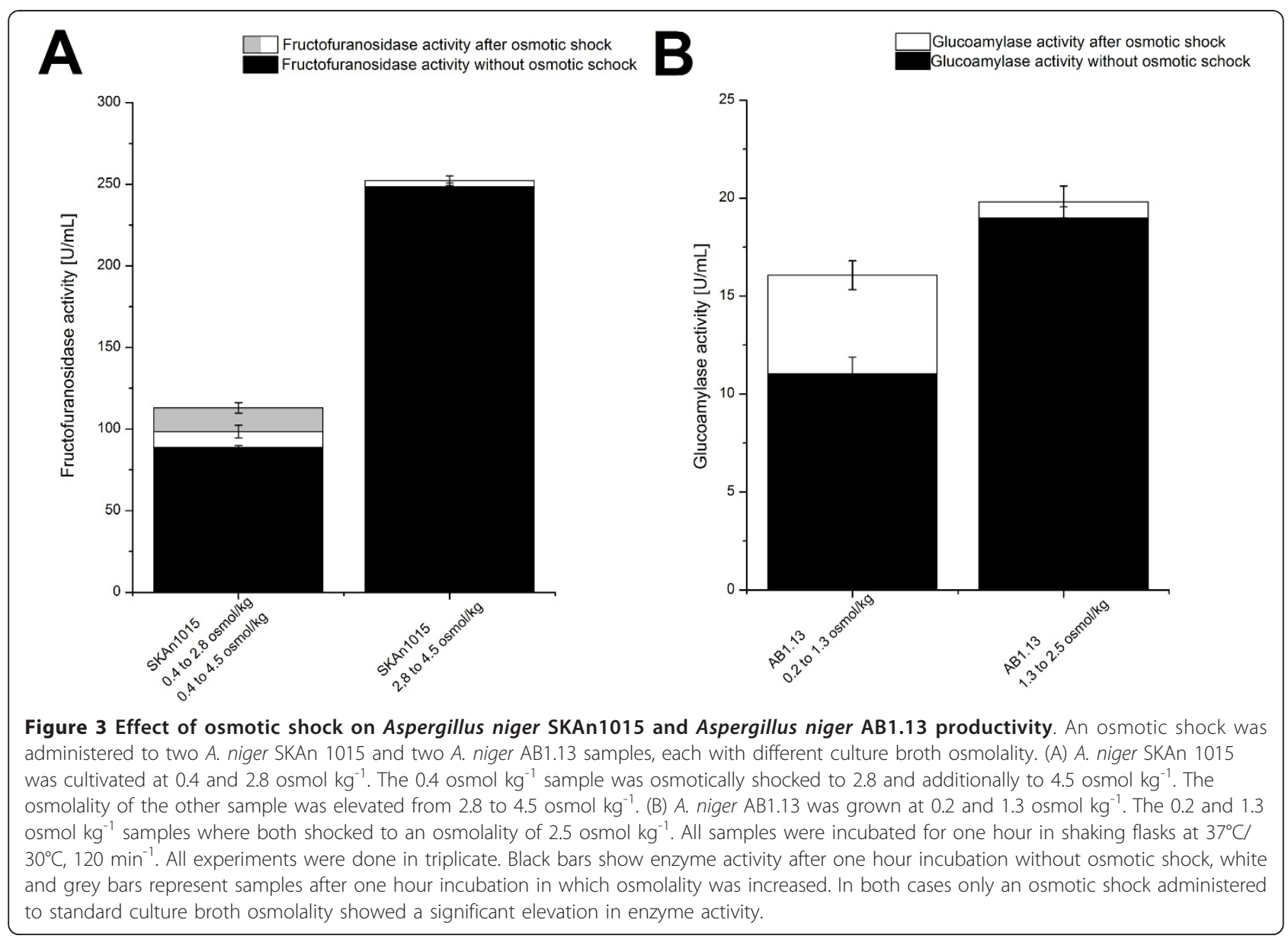


There are several other terms for osmolality used in the literature such as osmotic pressure, water potential, water activity or salt stress. The exact term used usually depends on the method of measurement and the area of research. It is arguable, if increased productivity is due to stress physiology. Whether the term "stress" is appropriate at all, depends further on the often unknown adaptation of a fungus to a highly osmotic environment. A non-adapted species will exhibit stress physiologies, an adapted may not [36]. Many soil fungi can survive extreme external water potentials down to about -20 MPa and some Aspergilli are even known to survive down to $-40 \mathrm{MPa}$ [37]. Aspergillus nidulans was shown by Beever et al. (1986) to exhibit optimal growth on $0.5 \mathrm{M} \mathrm{NaCl}$ basal medium, a growth rate of $50 \%$ on medium amended with $1.6 \mathrm{M} \mathrm{NaCl}$, and only little growth on medium amended with $3.4 \mathrm{M}$ sodium chloride [38]. Aspergilli in general were found to be notably resistant to high salt concentrations, as they were shown to grow in the presence of $20 \%$ or more of sodium chloride [39].

The Aspergillus strains used in this study might therefore not necessarily exhibit stress physiologies, which is supposedly responsible for a higher rate of protein synthesis. For clarification some genetic and molecular studies should be conducted. The maintenance of intracellular pressure, also called turgor, is somewhat critical for fungi, as it is the driving force for apical expansion and therefore fungal growth [40]. Cellular osmotolerance in general depends on the maintenance of osmotic gradients across the fungal cell membrane. Cellular water potentials have to be more negative than those in the external environment to maintain inwardly directed water transport [41]. This potential is usually generated through accumulation or synthesis of osmotically active solutes by the cell [36]. This could be a reason why osmotic shocks in this study were only successful when administered to culture broth at standard osmolality. In this case, the raised extracellular osmolality is likely to have caused an external water efflux, leading to a secretion of produced enzyme. Experiments in this study support this assumption, since an increase of culture broth osmolality from 0.4 to $4.5 \mathrm{osmol} \mathrm{\textrm {kg } ^ { - 1 }}$ led to a considerably higher fructofuranosidase activity, than an osmotic shock from 0.4 to 2.8 osmol kg-1 . Fungal biomass cultivated at higher osmolality will have accumulated a sufficient amount of compatible solutes to cope with the osmotic pressure of the medium. When this adapted fungal biomass is additionally exposed to an osmotic shock, no increased enzyme activity can be measured, because the cells are already used to coping with a highly osmotic environment. However, supplementary research is needed, for further clarification in this matter.
According to literature increase of osmotic pressure has been found to alter transport of substrates [27], causing an elevation in productivity. Furthermore, increased membrane permeability and secretion is believed to be responsible for a productivity raise through increased osmolality $[25,26]$. In this study, only bulk activity increased with raised osmotic pressure, while biomass associated activity increased only slightly (data not shown). Hence, it is likely, that more enzyme is secreted, substantiating results of earlier studies. Results in this study suggest additionally, that a permanent increase of culture broth osmolality is more beneficial for enzyme production, than osmotic shocks, because biomass cultivated at $2.8 \mathrm{osmol} \mathrm{\textrm {kg } ^ { - 1 }}$ generated much more enzyme activity than biomass cultivated in standard medium with a subsequent osmotic shock up to 2.8 osmol kg $^{-1}$ (Figure 3A).

Total soluble protein within the cultivation broth was considered, but not included in this study as high salinity interfered with common methods like Bradford protein assay or BCA protein assay. These problems, however, might be solved by ultrafiltration or dialysis pretreatment. In future studies soluble protein data should be included, as it provides information, whether only the produced protein or the total amount of protein is increased through high osmolality. Moreover, in future studies some protein should be purified to elucidate whether more enzyme is produced, or if the produced enzyme possesses a higher activity. A real time PCR might also be advisable, in order to clarify whether more enzyme mRNA is expressed.

\section{Characterization of fungal morphology}

A macro morphologic approach was chosen for characterization of fungal morphology. Micro morphology was not taken into account for reasons of practicability, since an easy reproducible method to characterize fungal morphology with statistical significance was preferred. Since mycelial morphology as investigated was in clumps or pellets, parameters of particle size and shape, like projected area, perimeter, circularity, solidity and aspect ratio were applied. Circularity is a parameter to quantify the closeness to a perfect circle. It is calculated as $4 \pi \frac{[\text { area }]}{[\text { perimeter }]^{2}}$, with a value of 1.0 indicating a perfect circle and an irregular object having a value closer to 0 . Solidity is a measure of the surface of a particle, also known as roughness. It is calculated by dividing the projected area through the convex area. The convex area being the area enveloped by the convex hull perimeter, which can be illustrated as an elastic band placed around the particle, determined by the software. A smooth shape has solidity of 1.0. Irregular objects tend 
to have a much lower value for solidity. Solidity is a good approximation of the surface area of the fungal pellet being available for mass transport. Aspect ratio is defined as major axis divided by minor axis and is a measure of elongation of a particle. A shape symmetrical in all axes such as a circle or square will have an elongation value of 1.0 whereas elongated particles will possess considerably larger values. A complete review of sample preparation, image analysis techniques and definitions was given by Paul and Thomas in their review on characterization of mycelial morphology using image analysis [42].

Figure 4A reveals an influence of osmolality on pellets size. The projected area of $A$. niger SKAn1015 is shown to decline with an increase in osmolality up to $4.2 \mathrm{osmol}$ $\mathrm{kg}^{-1}$. The standard deviation between the measured particles decreases at the same time, confirming the culture to be more homogenous at higher osmolalities. At an osmolality of 4.9 osmol kg-1 a perfect mycelial morphology was found which could not be further analyzed with the introduced image analysis parameters. In Figure 4B, the influence of osmolality on parameters of particle shape is depicted. Aspect ratio and the surface parameter solidity correlate well with osmolality. The parameter circularity is not significantly influenced by the raised osmotic pressure. Fungal particles get more elongated and their surface tends to be rougher at higher osmolality. The parameter solidity describes the particle roughness, and therefore the active surface of the clump or pellet. At higher sodium chloride concentrations fungal particles have considerably more active area. At 4.2 osmol kg-1 loose mycelial clumps were observed. An osmolality beyond that led to a pure mycelial morphology without any clumps or pellets.

The response of the other Aspergillus strain, AB1.13 was similar, although the sensitivity of this strain's morphology towards osmolality was much greater. For this strain an osmolality of only $2.4 \mathrm{osmol} \mathrm{kg}{ }^{-1}$ led to a perfect mycelial morphology. As with A. niger SKAn1015, A. niger AB1.13 pellets became smaller at higher osmotic pressure (Figure 5A). Standard deviation was generally higher in this experiment, because of the fewer cultivations conducted. Figure 5B demonstrates that AB1.13 morphology was affected in the same way by osmolality as $A$. niger SKAn1015 morphology. Fungal pellets became more elongated and generally increased their surface area while osmolality was raised. Morphology of both $A$. niger strains was shown to be considerably influenced by osmotic pressure. In all cases increased osmolality led to a more mycelial growth. Such morphological response has been previously described in literature [39] and is therefore unlikely to be limited to the investigated Aspergillus strains. Park et al. were able to show an influence of elevated salt concentrations on A. niger morphology, as sodium chloride caused the swelling of the hyphal tip and branch formation within the swollen region [43,44]. In a study of Kim et al., however, potassium chloride, up to a concentration of $1 \mathrm{M}$ had no effect on morphology of Aspergillus nidulans [45]. Other fungal strains like the halophilic Wallemia were found to be morphological

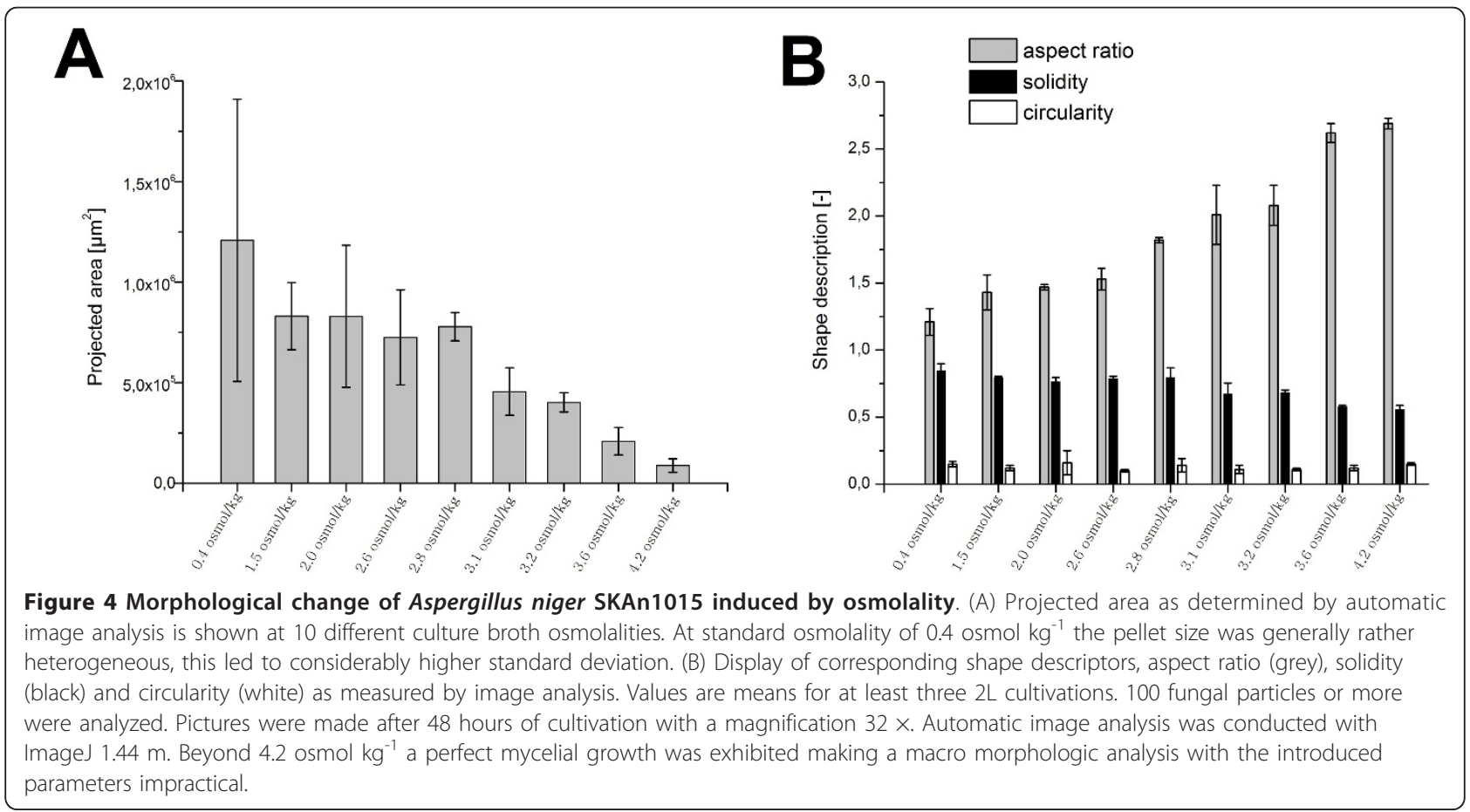



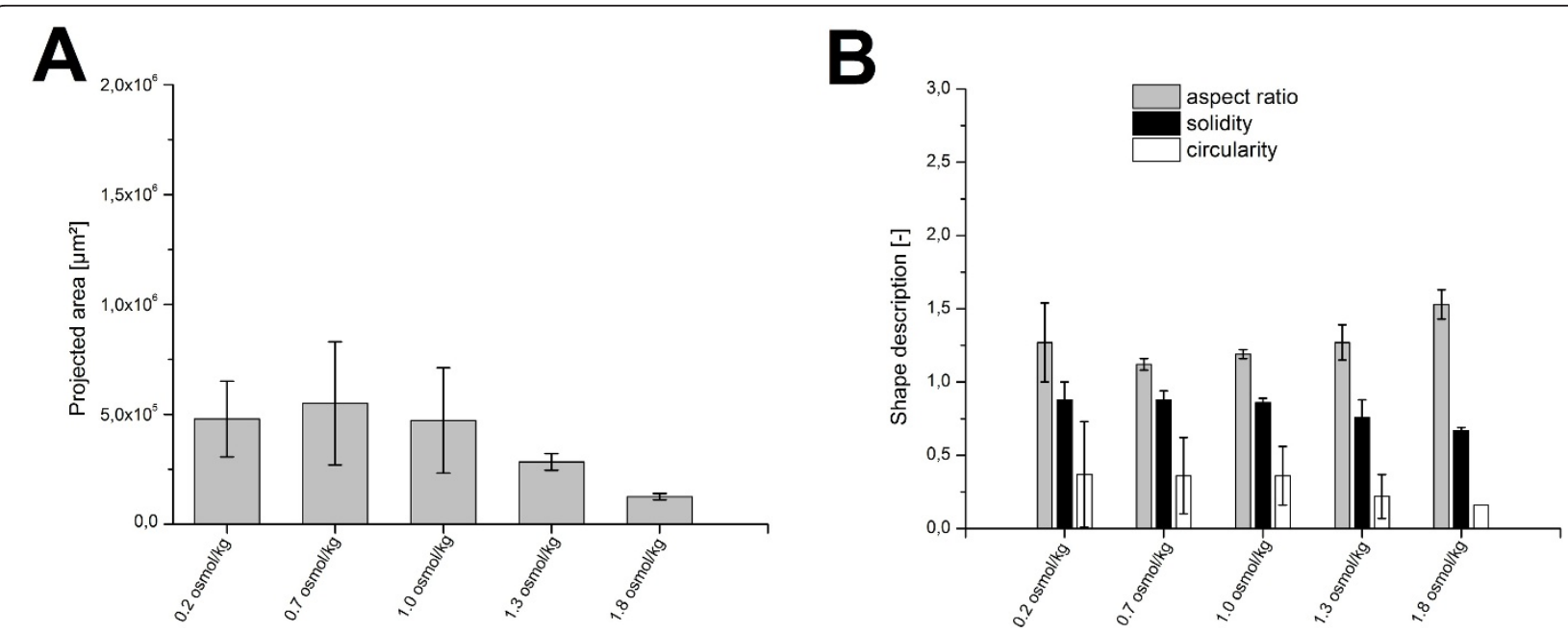

Figure 5 Morphological change of Aspergillus niger AB1.13 induced by osmolality. (A) Projected area as determined by automatic image analysis is shown at 5 different culture broth osmolalities. (B) Display of corresponding shape descriptors, aspect ratio (grey), solidity (black) and circularity (white) as measured by image analysis. Values are means for at least two $2 \mathrm{~L}$ cultivations. 100 fungal particles or more were analyzed. Pictures were made after 48 hours of cultivation with a magnification $32 \times$. Automatic image analysis was conducted with ImageJ $1.44 \mathrm{~m}$. Beyond $1.8 \mathrm{osmol} \mathrm{kg}{ }^{-1}$ fungal growth was perfectly mycelial, therefore macroscopic morphologic analysis conducted up to that value only.

sensitive to high salinity, as pellet size increased and wall thickness developed [46]. From the response of the examined fungi, it is rather likely that increased productivity and a more mycelial morphology are related. Image analytic methods have to be further improved; particularly in situ image acquisition as applied in Galindo et al. (2005) seems to be a promising approach [47]. Hereby the entity of fungal particles could be researched in their native state. Furthermore, a more precise structural analysis of $A$. niger morphology might be achieved by application of confocal laser scanning microscopy (CLSM) and scanning electron microscopy (SEM) providing superior surface characterization and thus allowing a more thorough image analysis [48]. Another promising approach seems to be the application of fractal analysis methods, though which the number of image analysis parameters could be possibly reduced [49].

\section{Correlation of morphology and productivity}

Since earlier results suggested an obvious correlation between fungal morphology and protein secretion, it was an objective in this study to link productivity to morphologic appearance. The macro morphology of filamentous fungi, the process of clump or pellet formation, was already shown to have significant impact on the measured mean activities and specific productivities [50]. In addition, macro morphology determines the micro-environment of hyphae through effects on mixing, mass transfer, and culture rheology which in turn affect protein production [22]. Fungal pellets, for instance, may have dense and inactive cores due to poor diffusion of nutrients, which may lead to cell lysis and thereby loss of the interior pellet structure
[51]. Microscopic morphology has other, indirect effects on productivity. Hyphal dimensions influence the secretion pathway [52] and protein secretion has been shown to be situated at the tips of fungal hyphae [53]. Wongwicharn et al. (1999) found heterologous enzyme secretion in $A$. niger to correlate with hyphal tip number as oxygen concentration was increased. Furthermore, they were able to show a correlation between the active area of the biomass and protein secretion [54]. Amanullah et al. (1999), in contrast found no direct effect of fungal morphology on protein secretion while researching the influence of agitation intensity [55].

Several parameters obtained by automatic image analysis in this study, like projected area, solidity and aspect ratio changed significantly with increased osmolality. However, too many parameters make quick assessment of fungal morphology complicated. Therefore an effort was undergone to combine relevant parameters from image analysis to a dimensionless Morphology number which can be used for a holistic characterization of morphology. Filamentous fungi can either grow as pellets or as mycelia. Between these extremes there is a whole span of intermediates, like elongated irregular pellets or clumps. Accordingly the following formula was introduced to combine the relevant morphological parameters observed:

$$
\text { morphology Number }=\frac{2 \cdot \sqrt{A} \cdot S}{\sqrt{\pi} \cdot D \cdot E}
$$

Where $\mathrm{A}$ is the projected area, $\mathrm{S}$ is the image analysis parameter solidity, $\mathrm{D}$ is the maximal diameter of the 
pellet and $\mathrm{E}$ is the elongation (aspect ratio) of the particle.

Perfectly round and smooth pellets will in microscopic images appear as perfect circles. For such particles the Morphology number has a value of 1 . The smallest fragment of mycelial morphology can be simplified as a onedimensional line yielding a Morphology number of zero. All intermediate morphological forms will therefore have values between 0 and 1 . Fairly large particles will result in a high, fungal particles with a large surface or elongated particles, in a rather low Morphology number. A fairly good correlation $\left(R^{2}=0.9\right)$ is obtained when plotting the Morphology number of all A. niger SKAn1015 cultivations against the specific productivity (Figure 6A) with an exponential fit of the form $y=a \cdot e^{b \cdot x}$. A small Morphology number therefore shows a high productivity. When the glucoamylase producing strain A. niger AB1.13 Morphology number is plotted against the corresponding productivity there is also a good correlation $\left(\mathrm{R}^{2}=0.86\right)$ (Figure 6B). In this case, however, notably less cultivations were conducted, as previously mentioned. Because of the more spherical particles of the AB1.13 strain, the Morphology number is slightly larger in comparison with the SKAn1015 strain.

It has to be noted, that observed changes in productivity might not be due to the change in morphology alone. The external parameter osmolality might have affected fungal physiology and through this morphology independent of each other. Observed productivity raise, however, was shown to correlate with the active surface area of the fungus, which is a good indication of plausibility. Besides osmolality several further parameters are known to influence fungal morphology, for the purpose of validation and usability the Morphology number should be tested with all of them, to proof it an authentic and reliable tool for macro morphologic description of fungal morphology.

\section{Influence of osmolality on $A$. niger conidia aggregation}

Different morphological growth forms of $A$. niger are believed to be related to differences in spore aggregation, whereas overall growth rate has no or a quite small impact on fungal morphology. Previous experiments showed that it will be decided in the first 8 hours, depending on culture conditions, whether $A$. niger grows in pellet or mycelial morphology. Later on fungal morphology will remain constant, even if culture conditions are changed. A. niger at standard conditions described in this study will never develop a mycelial morphology. Mycelium grown at $4.5 \mathrm{osmol} / \mathrm{kg}$, on the other hand, never forms fungal pellets. Even elongated fluffy pellets, which are crossover morphology, stay constant in their form and shape, if any changes in culture conditions take place after this first crucial period. Spore aggregation and subsequently germination are the most important parameters which determine fungal morphology and are therefore included in this study.

A profound effect of osmolality on germination was revealed, while researching the aggregation of $A$. niger conidia at several osmolalities from 0.35 to 3.6 osmol $\mathrm{kg}^{-1}$ (Figure 7). The median (top) and the Sauter mean diameter (SMD) (bottom) over time are given for representative cultivations. Graphics A through $\mathrm{H}$ show that spores germinate later at higher osmolalities. Furthermore the time difference between median and Sauter mean diameter (SMD) (grey) increases (Figure 7). Laser

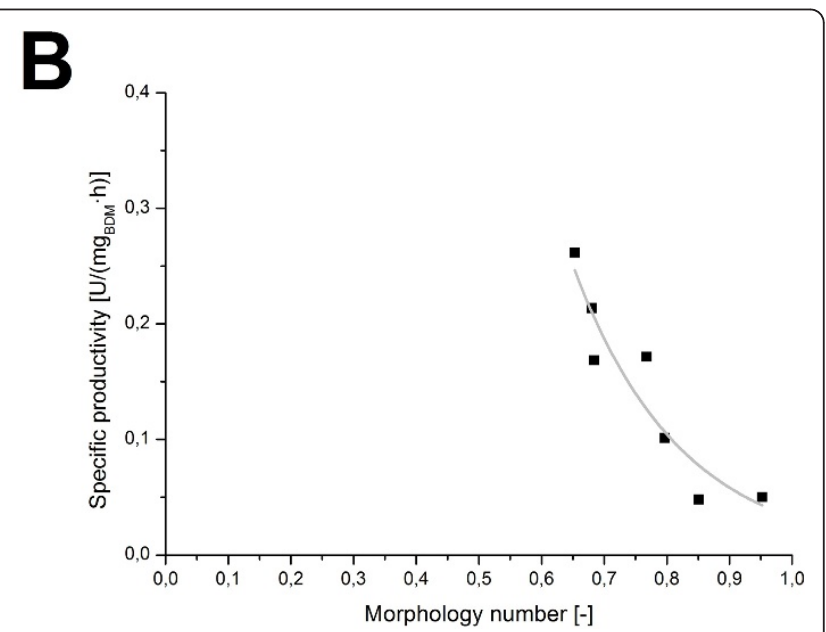

Figure 6 Correlation of fungal morphology with productivity. (A) Specific productivity of all conducted Aspergillus niger SKAn1015 cultivations is plotted over corresponding Morphology number $\left(R^{2}=0.9\right)$. An exponential fit produced a correlation of the form $y=6.83 \cdot e^{-2.94 \cdot x}$. (B) Specific productivity of all conducted Aspergillus niger AB1.13 cultivations is plotted over corresponding Morphology number $\left(R^{2}=0.86\right)$. The obtained correlation is $y=185.69 \cdot e^{-5.84 \cdot x}$. Each dot represents a single $2 \mathrm{~L}$ cultivation. 


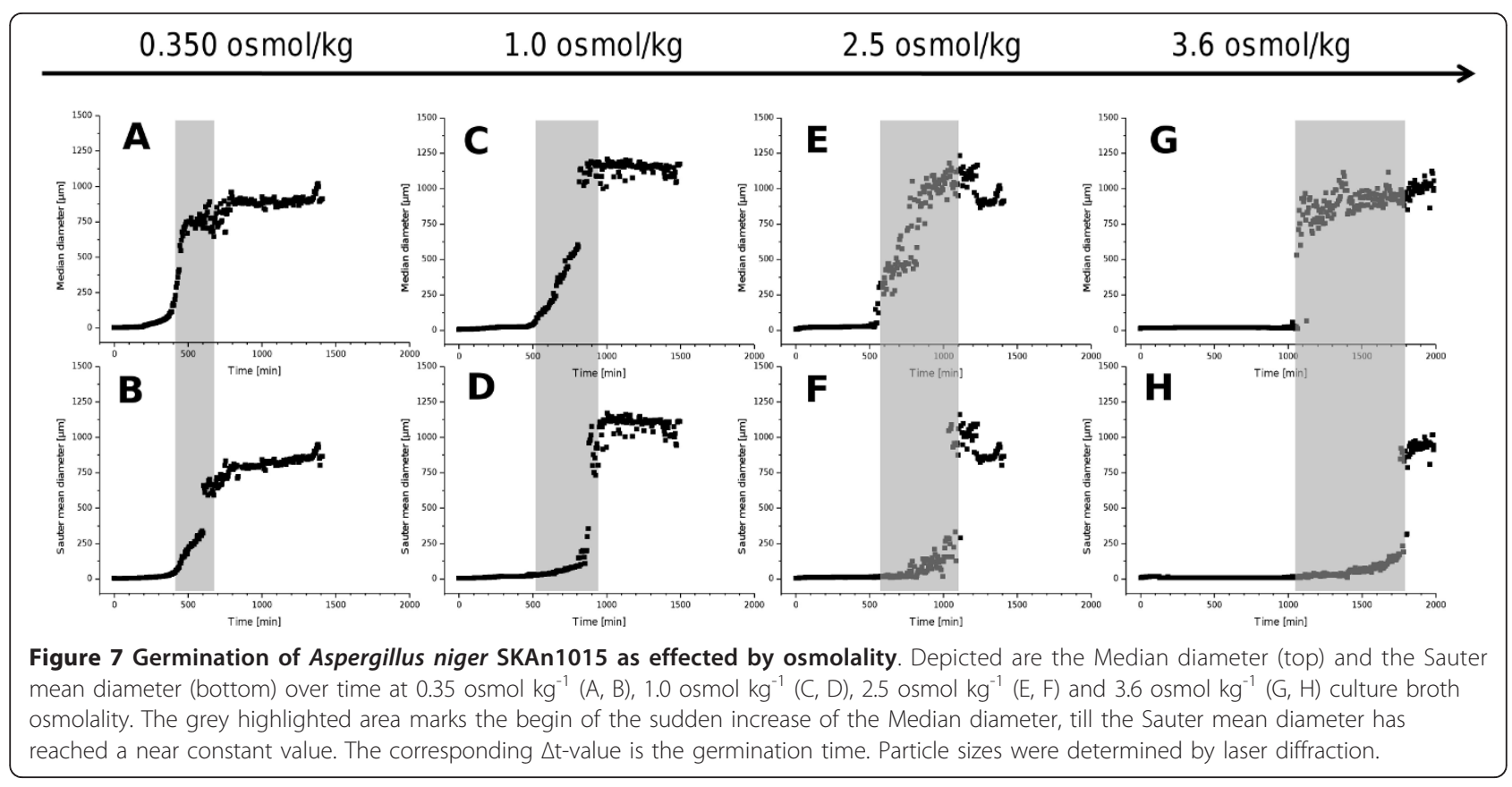

diffraction experiments were conducted without aeration, since bubble interfere with scattering patterns and cannot be differentiated from particles. This experiment was conducted, because conidia aggregation is believed to be one of the most important factors for development of fungal morphology. In earlier studies it was shown that oxygen requirement is very low in the first hours of germination and no oxygen limitation could be detected by measurement of dissolved oxygen [56]. Therefore omitting of aeration was feasible.

Germination of fungal spores can be split into three steps: germination, isotropic growth (swelling) and polarized growth, due the emergence of the germ tube [57]. The cultivation broth is inoculated with spores, which are small spherical particles. After germination, small elongated particles are formed, through the formation of a singular germ tube with a tubular shape (Figure 8) [58]. Subsequently clumps and pellets are formed which are larger and again more or less spherical particles [59]. Trinci et. al (1969) first showed a pronounced lag phase and almost linear germination afterwards [60]. The same can be observed in Figure 7, graphs A to $\mathrm{H}$. The definition of when a spore is germinated is based on a comparison between the length of the germ tube and the diameter of the spore. Germination time is the time until $90 \%$ of conidia have germinated, the exact percentage depending on the study [61].

In this study a novel approach was taken to examine conidia germination. Laser diffraction was employed to measure the size of sole conidia and conidia-aggregates. The method of laser diffraction generates volume equivalent distributions, which can be used to obtain statistical data, like the median. Laser diffraction, however, cannot differentiate between narrow elongated particles and larger spherical particles. Hence, germinating conidia will be recorded either as rather large particles measuring the

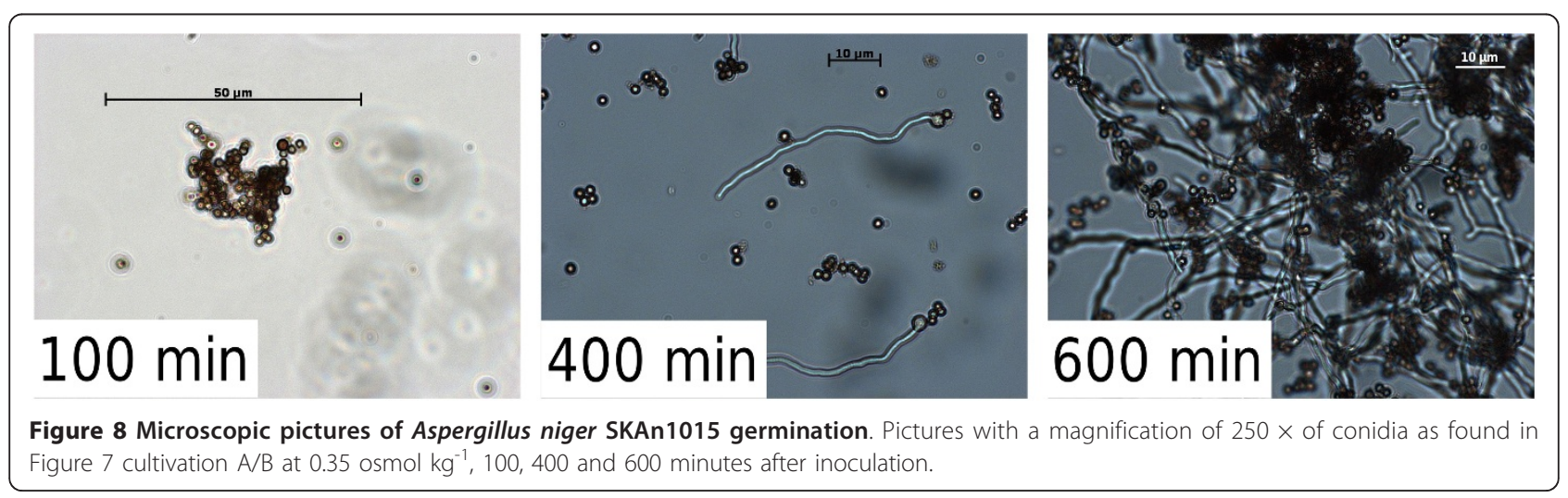


elongated side, or spore-like size particles when measuring the considerably smaller width of the germinating conidia. The median value of a measured particle size distribution changes abruptly as soon as germination occurs and the germ tube begins to emerge. In a relatively short time frame of approximately 60 minutes the median can be observed to increase (Figure 7) from around $3 \mu \mathrm{m}$, the size of $A$. niger conidia, to $1,000 \mu \mathrm{m}$, which is the size of germinated spore aggregates and later on the diameter of pellets. The reason for the sometimes deviating median values is the measuring method of laser diffraction. Fluid dynamic properties within the measuring cell determine which side of the particle is measured, sometimes leading to considerable differences in the measured diameter. In this experimental set up the median value can be used as an indication on when the conidia start to germinate, as an emerging germ tube (Figure 8) will instantly influence the measured mean diameter. Therefore, the lag phase is the time until the abrupt increase of the median.

The Sauter mean diameter is defined as a diameter of a particle that has the same volume/surface area ratio as a particle of interest. The SMD increases later and with less velocity than the median value (Figure 7), because smaller particles are weighted more heavily than in the median value. Thus, the Sauter mean diameter in this experiment can be interpreted as an indication on when the large majority of conidia have germinated. The time difference between the median diameter and the SDM is the germination time.

In Figure 9 lag phase and germination time as effected by osmolality are displayed. Increasing the osmolality of the cultivation broth leads to a prolonged lag phase and an almost linear increase in germination time (Figure 8).

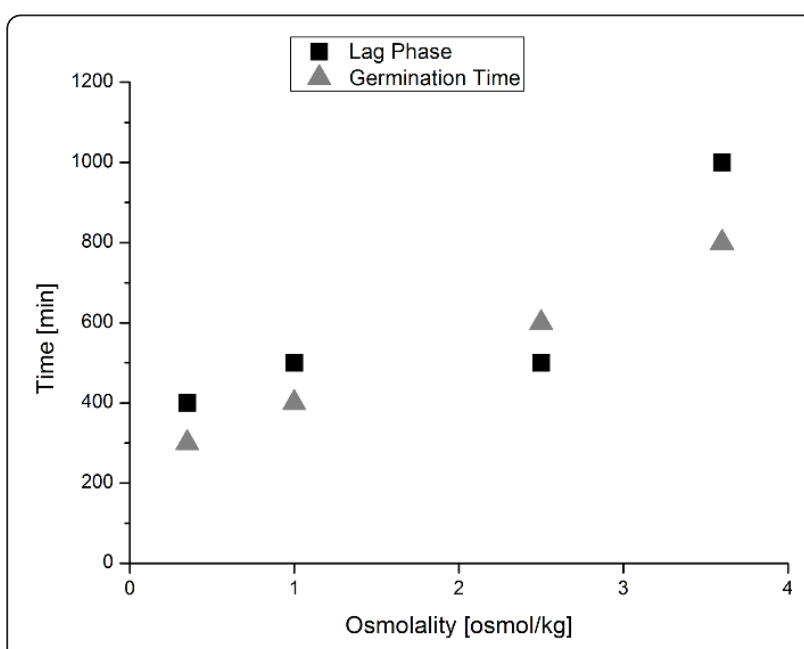

Figure 9 Influence of osmolality on germination time and lag phase. Germination time (grey triangle) and lag phase (black box) are depicted over osmolality.
Such a dependency was previously shown only on agar plates by Judet et al. (2008). The authors found that the germination time increased with decreasing water activity within the germination medium [62]. In submerse cultivations this prolonged germination process is most likely one reason for the considerable impact of osmolality on fungal morphology. Inoculum concentration was previously also shown to effect conidia germination by Grimm et al. (2004) and others. Both studies showed a prolonged germination time for increasing spore concentrations [59,63]. Inoculum concentration was also demonstrated to effect fungal morphology, as a higher number of spores led to more mycelial growth [64]. Thus at least for two parameters increased germination time leads to a more mycelial morphology. It would be interesting to determine, whether other parameters associated with mycelia morphology like low pH [65], or supplemented microparticles [17], also increase germination time of conidia. Moreover it should be an emphasis of future research, to determine, whether in submerged cultivation, a prolonged germination time and mycelia morphology are directly connected.

\section{Conclusions}

For industrial application it is crucial to distinguish between a well and a poorly producing fungal morphology. Through the introduction of the versatile Morphology number, this study provides the means for a desirable characterization of fungal morphology and demonstrates its relation to productivity. Furthermore, osmolality as a fairly new parameter in process engineering was introduced and found to affect fungal morphology and productivity. Osmolality might provide a cheap and reliable approach to increase the productivity in industrial processes. Because of the predictable behavior fungal morphology showed in dependence of osmolality, a customization of morphology for process needs seems feasible. Since rheology of culture broth and therewith downstream processing of the product are heavily dependent on fungal morphology, a tailor-made morphology could prove to be invaluable.

A novel method for determination of germination time in submerged cultivations, by laser diffraction was introduced in this study. Thus germination time of $A$. niger conidia was shown to increase with raised osmolality.

The Morphology number used in this study enables a very good characterization of fungal morphology. However, currently image analytic parameters in this study are adapted for characterization of inorganic particles and have their limitations when characterizing true mycelial morphology where no particles can be made out. Using the Morphology number, it is possible to distinguish between different pellet and clump morphologies in thoroughly and particle like and mycelial morphology can be 
differentiated. Nevertheless, it is not yet possible to compare two mycelial morphologies. To achieve this, new means have to be used. Determination of the fractal dimension also seems to be a promising method for holistic characterization of mycelial morphology.

\section{Methods}

\section{Microorganism and inoculum preparation}

Two recombinant strains of Aspergillus niger were used in this study. A. niger AB1.13 (van den Hondel, Universiteit Leiden, The Netherlands) is a glucoamylase producing, protease deficient, uridine auxotroph strain [66] derived from AB4.1 [67] by UV irradiation. A. niger SKAn1015 carrying the suc1 (fructofuranosidase) gene to produce fructofuranosidase under the control of the constitutive pkiA (pyruvate kinase) promoter was obtained from A. niger AB1.13 by transformation [34]. All organisms were maintained as frozen spore suspension at $-80^{\circ} \mathrm{C}$ in $50 \%$ glycerol. To obtain spores, agar plates with the sporulation medium were plated out with spores from a frozen stock (stored in $50 \%$ glycerin at $-80^{\circ} \mathrm{C}$ ) and incubated for five days at $30^{\circ} \mathrm{C}$. The sporulation medium for $A$. niger SKAn1015 contained $30 \mathrm{~g} \mathrm{~L}^{-1}$ potato dextrose agar (Sigma-Aldrich) and $10 \mathrm{~g} \mathrm{~L}^{-1}$ agar (Sigma-Aldrich). The sporulation medium for $A$. niger AB1.13 contained an additional $1 \mathrm{~g} \mathrm{~L}^{-1}$ uridine.

After growth and sporulation, $30 \mathrm{~mL}$ sterile $\mathrm{NaCl}$ solution $(0.9 \% \mathrm{w} / \mathrm{v})$ was added to each agar plate, which was scraped to release the aerial mycelium. The suspension was filtered through two layers of sterile Miracloth (pore size 22 to $25 \mu \mathrm{m}$, Merck) to prevent agar debris and conidiophores in the spore suspension. The optical density of the spore suspension was measured photometrically at $600 \mathrm{~nm}$ (SmartSpec ${ }^{\mathrm{TM}} 3000$, BioRad) and converted to spore concentration $\left(\mathrm{m} \mathrm{L}^{-1}\right)$ by a predetermined calibration curve.

\section{Media and cultivation conditions}

A modified Vogel-Medium with the composition listed as follows (in $\mathrm{g} \mathrm{L}^{-1}$ ) was used as the growth medium for all A. niger AB1.13 cultivations: glucose 20.0; uridine 0.244; $50 \mathrm{~mL} \mathrm{~L}^{-1}$ salt solution containing $132 \mathrm{~g} \mathrm{~L}^{-1}\left(\mathrm{NH}_{4}\right)_{2} \mathrm{SO}_{4}$; $50 \mathrm{~g} \mathrm{~L}^{-1} \quad \mathrm{KH}_{2} \mathrm{PO}_{4} ; 4 \mathrm{~g} \mathrm{~L}^{-1} \mathrm{MgSO}_{4} \cdot 7 \mathrm{H}_{2} \mathrm{O} ; 2 \mathrm{~g} \mathrm{~L}^{-1}$ $\mathrm{CaCl}_{2} \cdot 2 \mathrm{H}_{2} \mathrm{O}$ and $0.1 \mathrm{~mL} \mathrm{~L}^{-1}$ trace element solution containing: $50 \mathrm{~g} \mathrm{~L}^{-1} \mathrm{C}_{6} \mathrm{H}_{8} \mathrm{O}_{7} \cdot \mathrm{H}_{2} \mathrm{O} ; 50 \mathrm{~g} \mathrm{~L}^{-1} \mathrm{ZnSO}_{4} \cdot 7 \mathrm{H}_{2} \mathrm{O} ; 10 \mathrm{~g}$ $\mathrm{L}^{-1} \mathrm{Fe}\left(\mathrm{NH}_{4}\right)_{2}\left(\mathrm{SO}_{4}\right)_{2} \cdot 6 \mathrm{H}_{2} \mathrm{O} ; 1.6 \mathrm{~g} \mathrm{~L}^{-1} \mathrm{CuSO}_{4} ; 0.5 \mathrm{~g} \mathrm{~L}^{-1}$ $\mathrm{H}_{3} \mathrm{BO}_{3} ; 0.5 \mathrm{~g} \mathrm{~L}^{-1} \mathrm{Na}_{2} \mathrm{MoO}_{4} \cdot \mathrm{H}_{2} \mathrm{O} ; 0.37 \mathrm{~g} \mathrm{~L}^{-1} \mathrm{MnSO}_{4} \cdot \mathrm{H}_{2} \mathrm{O}$. The salt solution and the trace element solution were sterilized separately and added aseptically to the sterilized bioreactor with the remainder of the medium. The cultivation medium of $A$. niger SKAn1015 contained per liter 20 g D-glucose as $20 \mathrm{~mL}$ salt solution $\left(6 \mathrm{~g} \mathrm{~L}^{-1} \mathrm{NaNO}_{3}, 0.5 \mathrm{~g}\right.$ $\left.\mathrm{L}^{-1} \mathrm{KCI}, 1.5 \mathrm{~g} \mathrm{~L}^{-1} \mathrm{KH}_{2} \mathrm{PO}_{4}, 0.5 \mathrm{~g} / \mathrm{L} \mathrm{MgSO}_{4} \cdot 7 \mathrm{H}_{2} \mathrm{O}\right)$ and 1
$\mathrm{mL}$ trace element solution $\left(10 \mathrm{mg} / \mathrm{L}\right.$ EDTA, $4.4 \mathrm{mg} \mathrm{L}^{-1}$ $\mathrm{ZnSO}_{4} \cdot 7 \mathrm{H}_{2} \mathrm{O}, 1.01 \mathrm{mg} / \mathrm{L} \quad \mathrm{MnCl}_{2} \cdot 4 \mathrm{H}_{2} \mathrm{O}, 0.32 \mathrm{mg} / \mathrm{L}$ $\mathrm{CuSO}_{4} \cdot 5 \mathrm{H}_{2} \mathrm{O}, 1 \mathrm{mg} / \mathrm{L} \quad \mathrm{FeSO}_{4} \cdot 7 \mathrm{H}_{2} \mathrm{O}, 0.32 \mathrm{mg} \mathrm{L}^{-1}$ $\mathrm{CoCl}_{2} \cdot 6 \mathrm{H}_{2} \mathrm{O}, 1.47 \mathrm{mg} \mathrm{L}^{-1} \mathrm{CaCl}_{2} \cdot 2 \mathrm{H}_{2} \mathrm{O}$, and $0.22 \mathrm{mg} \mathrm{L}^{-1}$ $\left.\left(\mathrm{NH}_{4}\right) 6 \mathrm{Mo}_{7} \mathrm{O}_{24} \cdot 4 \mathrm{H}_{2} \mathrm{O}\right)$. Carbon source, salt, and trace element solutions were autoclaved separately at $121^{\circ} \mathrm{C}$ for $20 \mathrm{~min}$ and chilled to room temperature prior to mixing and use.

Batch cultivations were carried out in a 3-L stirred tank bioreactor (Applikon, Schiedam, The Netherlands) with two six-bladed disc turbine impellers. Bioreactors were inoculated with a suspension of freshly harvested conidia to give a spore concentration of $1 \cdot 10^{6} \mathrm{~mL}^{-1}$ after inoculation. All bioreactor cultivations were carried out at least in triplicate. Growth temperature was $37 \pm 0.1^{\circ} \mathrm{C}(A$. niger SKAn1015) and $30 \pm 0.1^{\circ} \mathrm{C}$ (A. niger AB1.13). Aeration rate $\left(1.0 \mathrm{~L} \mathrm{~min}{ }^{-1}\right)$, agitation speed $\left(200 \mathrm{~min}^{-1}\right)$ and $\mathrm{pH}$ value ( $\mathrm{pH}$ 5.0) were automatically kept constant.

\section{Biomass concentration, osmolality, enzymatic assays and statistical analysis}

The biomass dry weight was measured gravimetrically by filtering (Nalgene 300-4000) a defined amount of biomass suspension through a pre-dried $\left(48 \mathrm{~h}\right.$ at $\left.105^{\circ} \mathrm{C}\right)$ and pre-weighted suction filter (Filter Discs Grade 389, Sartorius). Prior to drying $\left(48 \mathrm{~h}\right.$ at $\left.105^{\circ} \mathrm{C}\right)$, the filter was rinsed several times with deionized water to remove medium components from the biomass. The biomass dry weight concentration $\left(\mathrm{g} \mathrm{L}^{-1}\right)$ was calculated as the difference between the weight of the filter with and without dried biomass divided by the sample volume.

In this work the unit osmolality (osmol $\mathrm{kg}^{-1}$ ) instead of the more common osmolarity (osmol L-1) was used, since osmolality, lacking a volumetric unit, is not as temperature sensitive as osmolarity. The osmolality of the standard

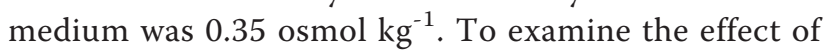
osmotic pressure this standard osmolality was adjusted permanently to the desired value by addition of sodium chloride. Osmolality was monitored regularly during cultivation. For determination of osmolality, $50 \mu \mathrm{l}$ of bulk sample were analyzed by freezing-point depression using an Osmometer (Osmomant 030, Gonotec).

Glucoamylase (GA, 1,4- $\alpha$-D-glucan glucohydrolase, EC 3.2.1.3) activity was analyzed with the PNPG (4-nitrophenyl- $\alpha$-D-glycopyranoside, Fluka) method described by Withers et al. [68] based on a spectrophotometeric analysis of 4-nitrophenol, which is formed by the reaction of GA with the colorless PNPG and appears yellow under alkaline conditions with an absorbance maximum at $400 \mathrm{~nm}$. Extraparticulate GA activity was determined by measuring the enzyme activity in the culture supernatant obtained by sterile filtration (minisart syringe filter, Sartorius). Intraparticulate activity was quantified by 
separating the pellets of a given sample volume from the culture supernatant, washing them with deionized water and disintegrating them with a mortar mill (RM100, Retsch) in the equivalent buffer volume. The suspension obtained was assayed for its enzyme activity.

The specific activity of fructofuranosidase of bulk culture was quantified by filtration of $1.5 \mathrm{~mL}$ culture broth through a cellulose acetate filter (pore size $0,2 \mu \mathrm{m}$, Sartorius). The reaction mixture $(220 \mu \mathrm{L})$ consisted of $200 \mu \mathrm{L}$ $1.65 \mathrm{M}$ sucrose dissolved in $0.05 \mathrm{M}$ phosphate buffer $(\mathrm{pH}$ 5.4) and $20 \mu \mathrm{L}$ sample. Reaction was initiated by addition of $200 \mu \mathrm{L}$ sucrose to a $20 \mu \mathrm{L}$ sample and incubated at $40^{\circ} \mathrm{C}$ for $20 \mathrm{~min}$. The reaction was stopped by heating at $95^{\circ} \mathrm{C}$ for $10 \mathrm{~min}$. After cooling, the reaction mixture was centrifuged at $13,000 \mathrm{~g}$ for $10 \mathrm{~min}$ at $4{ }^{\circ} \mathrm{C}$. Glucose formed from cleavage of sucrose by fructofuranosidase was then quantified using a GOD/POD assay (Sigma-Aldrich) [69], which was modified for high-throughput analysis in 96well microtiter plates (MaxiSorp, Nunc, Langenselbold, Germany). For this assay an enzyme reagent solution was prepared by re-suspending $10.5 \mathrm{mg}$ glucose oxidase (GOD) and $3 \mathrm{mg}$ of peroxidase (POD) in $90 \mathrm{~mL}$ of $0.05 \mathrm{M}$ phosphate buffer (pH 7.0) and $10 \mathrm{~mL}$ of $95 \%$ ethanol containing $25 \mathrm{mg}$ of o-dianosidine, respectively. Subsequently, the reagent solution was filtered through a cellulose acetate filter (pore size $20 \mathrm{~mm}$, Sartorius) and immediately used for the assay. For this purpose, $2 \mu \mathrm{L}$ sample was mixed with $200 \mu \mathrm{L}$ of the reagent solution in a microtiter plate well. After $10 \mathrm{~min}$ incubation at room temperature, glucose was quantified indirectly through absorption measurement at $450 \mathrm{~nm}$ using a 96-well Sunrise microplate reader (TECAN, Crailsheim, Germany) and the XFlour4 data retrieval software. To account for residual glucose in the culture broth, negative controls were carried out by using samples in which fructofuranosidase was inactivated by heating at $95^{\circ} \mathrm{C}$ for $10 \mathrm{~min}$ prior to incubation. All enzymatic assays were done in triplicate.

To test for statistically significant differences between cultivation of different osmolality the Monte Carlo method was applied [70]. Sample data, within the standard error previously determined by experimentation, was evaluated using Matlab (MathWorks, United States). The data sets were used in a paired t-test conducted with Origin (Originlab, United States), to test for statistical difference between data sets.

\section{Microscopy and image analysis}

Throughout the cultivation culture morphology was monitored offline using a stereo-microscope (Stemi 2000-C, ZEISS, Jena, Germany) with an AxioCamMRc5 camera (ZEISS, Jena, Germany). The pellets were suspended individually in a Petri dish filled with diluted cultivation medium, several images of fungal particles were acquired. Around 100 pellets were analyzed for each sample. Image analysis and characterization was carried out using the ImageJ 1.44 software that is available in the public domain [71]. ImageJ was chosen in this study for its robustness and versatility and the more than 400 plugins available to fit the program to personal needs [72]. Each image was converted into an 8-bit grey-scale image. Subsequently a grey-level threshold, calculated by ImageJ using the Otsu algorithm, was applied, resulting in a binary image which was later analyzed using the inbuilt analyze particles function. Only macromorphologic parameters were considered for image analysis. The morphological parameters evaluated were projected area, perimeter, circularity, solidity, and aspect ratio for mycelial aggregates (clumps and pellets).

\section{Parameters used for determination of cultivation performance}

Cultivation performance was in general judged by the activity of the produced enzyme. As units, the yield per volume of cultivation broth $\left(\mathrm{U} \mathrm{mL}^{-1}\right)$ and specific yield per biomass cell weight $\mathrm{U} \mathrm{mg}^{-1}$ were measured at the end of cultivation. For determination of specific productivity the growth curve of the microorganism, using biomass dry weight (BDW), as biomass was integrated, yielding the biomass dry weight integral (BDWI).

$$
\text { Biomass Dry Weight Integral }(B D W I)=\int_{t 1}^{t 2} B D W \cdot d t
$$

The BDWI was therefore calculated by:

$$
B D W I_{t 2}=B D W I_{t 1}+\left[\frac{\left(B D W_{t 1}+B D W_{t 2}\right)}{2} \cdot\left(t_{2}-t_{1}\right)\right]
$$

Subsequently the specific productivity $\left(\mathrm{U} \mathrm{mg}^{-1} \mathrm{~h}^{-1}\right)$ was obtained by plotting the enzymatic activity of the enzyme over the BDWI, providing an approximate linear relationship with the slope being equal to the specific productivity of the process:

$$
\text { Specific productivity }=\frac{d U}{d B D W I}
$$

\section{Measurement of particle size distribution for characterization of spore aggregation}

A laser diffraction technique (Mastersizer 2000, Malvern) was applied to analyze the aggregation of spores. This system basically comprised a helium-neon laser $(\lambda$ $=632.8 \mathrm{~nm}$ ) as a radiation source, which illuminated the dispersed pellets in the measuring zone and a series of detectors to measure the light pattern produced over a wide range of angles. The lower limit of the 
obscuration was set to $5 \%$, which was high enough to achieve a good signal to the noise ratio; the upper limit being $30 \%$, which was below the limit defined by the detector dynamics and the algorithm treating multiple scattering. The cultivation medium (dispersant) was assessed to possess the optical properties of water. Both scattering angle and scattering intensity were dependent on the pellet size. The diffraction of the laser light on the dispersed pellets resulted in a specific diffraction pattern, which was collected by the detectors and recorded by the software (Mastersizer 2000, version 5.60). By applying an appropriate optical model (Fraunhofer Approximation) to calculate the scattering pattern and a mathematical de-convolution procedure, the volumetric particle size distribution that best matched the measured scattering pattern was calculated.

For measurement of particle size, culture broth was pumped permanently from a 2-L stirred tank stirred tank bioreactor with a double Rushton turbine (Applikon, Schiedam, Netherlands), maintained at $\mathrm{pH}$ 5, without aeration, through the Mastersizer measuring cell. A peristaltic pump specifically designed for gentle pumping (Pro-280 MCP, Ismatec) was used in the process. In early experiments the pump was shown to have no influence on particle size. Sample measurement time was 15 seconds, resulting in a total of 15,000 snaps to be averaged, with an interval of 285 seconds between measurements. Around 400 measurements were made during a cultivation, which was conducted until pellet formation was completed at a median particle diameter of around $1,000 \mu \mathrm{m}$.

\section{Abbreviations}

BDW: biomass dry weight; BDWl: biomass dry weight integral; $D_{\text {max }}$ : maximal pellet diameter; GA: glucoamylase; SMD: Sauter mean diameter; $\mu_{\max }$ maximal growth rate

\section{Acknowledgements}

The authors gratefully acknowledge financial support provided by the German Research Foundation (DFG) through the collaborative research center SFB 578 "From Gene to Product" at the Technische Universität Braunschweig, Germany. We are grateful to Manely Eslahpazir for providing help in drafting the manuscript and Judith Becker for aiding in statistical analysis of acquired data.

\section{Authors' contributions}

TW had the idea for the study, did the literature review and prepared the manuscript. He also did some of the analysis, supervised the experiments and did the aggregation experiments. TH did the main lab work, cultivations and enzyme essays. Figures were prepared by TW and TH together. RK supervised the study, and participated in its design and coordination and helped to draft the manuscript. All authors read and approved the final manuscript.

\section{Competing interests}

The authors declare that they have no competing interests.

Received: 8 April 2011 Accepted: 29 July 2011 Published: 29 July 2011

\section{References}

1. Grimm LH, Kelly S, Krull R, Hempel DC: Morphology and Productivity of Filamentous Fungi. Appl Microbiol Biotechnol 2005, 69(4):375-384.

2. Lubertozzi D, Keasling JD: Developing Aspergillus as a host for heterologous expression. Biotechnol Adv 2009, 27(1):53-75.

3. Papagianni M: Fungal morphology and metabolite production in submerged mycelial processes. Biotechnol Adv 2004, 22(3):189-259.

4. Papagianni M, Mattey M, Kristiansen B: Citric acid production and morphology of Aspergillus niger as functions of the mixing intensity in a stirred tank and a tubular loop bioreactor. Biochem Eng J 1998, 2:197-205.

5. Papagianni $M$, Mattey $M$, Kristiansen $B$ : The influence of glucose concentration on citric acid production and morphology of Aspergillus niger in batch and glucostat culture. Enzyme Microb Technol 1999, 25:710-717.

6. Paul GC, Priede MA, Thomas CR: Relationship between morphology and citric acid production in submerged Aspergillus niger fermentations. Biochem Eng J 1999, 3:121-129.

7. Punt PJ, van Biezen N, Conesa A, Albers A, Mangnus J, van den Hondel C: Filamentous fungi as cell factories for heterologous protein production. Trends Biotechnol 2002, 20(5):200-206.

8. Casas López JL, Sánchez Pérez JA, Fernández Sevilla JM, Rodríguez Porcel EM Chisti Y: Pellet morphology, culture rheology and lovastatin production in cultures of Aspergillus terreus. J Biotechnol 2005, 116(1):61-77.

9. Gupta K, Mishra P, Srivastava P: A correlative evaluation of morphology and rheology of Aspergillus terreus during lovastatin fermentation. Biotechnol Bioprocess Eng 2007, 12(2):140-146.

10. Kim JH, Lebeault JM, Reuss M: Comparative study on rheological properties of mycelial broth in filamentous and pelleted forms. Appl Biochem Biotechnol 1983, 18(1):11-16.

11. Pazouki M, Panda T: Understanding the morphology of fungi. Bioproc Biosys Eng 2000, 22(2):127-143.

12. Gibbs PA, Seviour RJ, Schmid F: Growth of Filamentous Fungi in Submerged Culture: Problems and Possible Solutions. Crit Rev Biotechnol 2000, 20(1):17-48.

13. Kaup B-A, Ehrich K, Pescheck M, Schrader J: Microparticle-enhanced cultivation of filamentous microorganisms: Increased chloroperoxidase formation by Caldariomyces fumago as an example. Biotechnol and Bioeng 2008, 99(3):491-498.

14. Krull R, Cordes C, Horn H, Kampen I, Kwade A, Neu TR, Nörtemann B: Morphology of filamentous fungi - Linking cellular biology to process engineering using Aspergillus niger. Adv Biochem Eng/Biotechnol 2010, 121(116): $1-21$.

15. Zhang Z, Jin B, Kelly J: Effects of cultivation parameters on the morphology of Rhizopus arrhizus and the lactic acid production in a bubble column reactor. Eng Life Sci 2007, 7:490-496.

16. McIntyre M, Muller C, Dynesen J, Nielsen J: Metabolic engineering of the morphology of Aspergillus. Adv Biochem Eng/Biotechnol 2001, 73:103-128.

17. Driouch $\mathrm{H}$, Sommer B, Wittmann C: Morphology engineering of Aspergillus niger for improved enzyme production. Biotechnol Bioeng 2009, 105(6):1058-1068

18. Kelly S, Grimm LH, Bendig C, Hempel DC, Krull R: Effects of fluid dynamic induced shear stress on fungal growth and morphology. Proc Biochem 2006, 41:2113-2117.

19. Lin P-J, Scholz A, Krull R: Effect of volumetric power input by aeration and agitation on pellet morphology and product formation of Aspergillus niger. Biochem Eng J 2010, 49(2):213-220.

20. Rocha-Valadez JA, Galindo E, Serrano-Carreón L: The influence of circulation frequency on fungal morphology: A case study considering Kolmogorov microscale in constant specific energy dissipation rate cultures of Trichoderma harzianum. J Biotechnol 2007, 130(4):394-401.

21. Znidarsic P, Pavko A: The Morphology of Filamentous Fungi in Submerged Cultivations as a Bioprocess Parameter. Food Technol Biotechnol 2001, 39:237-252.

22. Wucherpfennig T, Kiep KA, Driouch H, Wittmann C, Krull R: Morphology and Rheology in Filamentous Cultivations. In Adv Appl Microbiol. Volume 72. Edited by: Allen I, Laskin SS, Geoffrey MG. Academic Press; 2010:89-136.

23. Allaway AEaJ DH: The influence of cations on glucose transport and metabolism by, and the loss of sugars alcohols from, the fungus Dendryphiella salina. New Phytol 1970, 69:581-593.

24. Allaway AEaJ DH: The effect of cations on glucose utilization by, and on the growth of, the fungus Dendryphiella salina. New Phytol 1971, 70:511-518. 
25. Bobowicz-Lassociska T, Grajek W: Changes in protein secretion of Aspergillus niger caused by the reduction of the water activity by potassium chloride. Acta Biotechnol 1995, 15(3):277-287.

26. Fiedurek J: Effect of osmotic stress on glucose oxidase production and secretion by Aspergillus niger. J Basic Microbiol 1998, 38(2):107-112.

27. Lee GM, Park SY: Enhanced specific antibody productivity of hybridomas resulting from hyperosmotic stress is cell line-specific. Biotechnol Lett 1995, 17(2):145-150.

28. Lee M, Lee G: Effect of hypoosmotic pressure on cell growth and antibody production in recombinant Chinese hamster ovary cell culture. Cytotechnology 2001, 36(1):61-69.

29. Oh SKW, Vig P, Chua F, Teo WK, Yap MGS: Substantial overproduction of antibodies by applying osmotic pressure and sodium butyrate. Biotechnol and Bioeng 1993, 42(5):601-610.

30. Ozturk SS, Palsson BO: Effect of medium osmolarity on hybridoma growth, metabolism, and antibody production. Biotechnol and Bioeng 1991, 37(10):989-993

31. Shen D, Kiehl TR, Khattak SF, Li ZJ, He A, Kayne PS, Patel V, Neuhaus IM, Sharfstein ST: Transcriptomic responses to sodium chloride-induced osmotic stress: A study of industrial fed-batch $\mathrm{CHO}$ cell cultures. Biotechnol Progr 2010, 26(4):1104-1115.

32. Fernandez RC, Ottoni CA, da Silva ES, Matsubara RM, Carter JM, Magossi LR, Wada MA, de Andrade Rodrigues MF, Maresma BG, AE M: Screening of -fructofuranosidase-producing microorganisms and effect of $\mathrm{pH}$ and temperature on enzymatic rate. Appl Microbiol Biotechnol 2007, 75:87-93.

33. Maiorano A, Piccoli R, da Silva E, de Andrade Rodrigues M: Microbial production of fructosyltransferases for synthesis of pre-biotics. Biotechnol Lett 2008, 30(11):1867-1877.

34. Zuccaro A, Götze S, Kneip S, Dersch P, Seibel J: Tailor-Made Fructooligosaccharides by a Combination of Substrate and Genetic Engineering. ChemBioChem 2008, 9(1):143-149.

35. Emmler M, Jungebloud A, Göcke Y, Cordes C, Horn H, Hempel DC: Apparent Delay of Product Secretion by Product Adsorption in Aspergillus niger. Eng Life Sci 2006, 6(5):488-491.

36. Hooley P, Fincham DA, Whitehead MP, Clipson NJW: Fungal Osmotolerance. In Adv Appl Microbiol. Volume 53. Edited by: Allen I, Laskin JWB, Geoffrey MG. Academic Press; 2003:177-211.

37. Griffin DH: Fungal Physiology. 2 edition. New York.: Wiley-Liss; 1994.

38. Beever RE, Laracy EP: Osmotic adjustment in the filamentous fungus Aspergillus nidulans. J Bacteriol 1986, 168(3):1358-1365.

39. Tresner HD, Hayes JA: Sodium chloride tolerance of terrestrial fungi. Appl Microbiol 1971, 22(2):210-213.

40. Money NP: Wishful Thinking of Turgor Revisited: The Mechanics of Fungal Growth. Fungal Genetics and Biology 1997, 21(2):173-187.

41. Clipson NJW, Jennings DH: Dendryphiella salina and Debaryomyces hansenii: models for ecophysiological adaptation to salinity by fungi which grow in the sea. Can J Bot 1992, , 70: 2097-2105.

42. Paul G, Thomas C: Characterisation of mycelial morphology using image analysis. Adv Biochem Eng/Biotechnol 1998, 1-59.

43. Park J-C, Matsuoka H, Takatori K, Kurata H: Adaptation of Aspergillus niger to acidic conditions and its relationship to salt stress and miconazole. Mycological Research 1996, 100(7):869-874.

44. Park J-C, Nemoto Y, Homma T, Jing W, Chen Y, Matsuoka H, Ohno H, Takatori K, Kurata H: Adaptation of Aspergillus niger to short-term salt strees. Appl Microbiol Biotechnol 1993, 40(2):394-398.

45. Kim Y, Nandakumar MP, Marten MR: Proteome map of Aspergillus nidulans during osmoadaptation. Fungal Genetics and Biology 2007, 44(9):886-895.

46. Kralj Kuncic M, Kogej T, Drobne D, Gunde-Cimerman N: Morphological Response of the Halophilic Fungal Genus Wallemia to High Salinity. Appl Environ Microbiol 2010, 76(1):329-337.

47. Galindo E, Larralde-Corona CP, Brito T, Córdova-Aguilar MS, Taboada B, Vega-Alvarado L, Corkidi G: Development of advanced image analysis techniques for the in situ characterization of multiphase dispersions occurring in bioreactors. J Biotechnol 2005, 116(3):261-270.

48. Villena GK, Fujikawa T, Tsuyumu S, Gutiérrez-Correa M: Structural analysis of biofilms and pellets of Aspergillus niger by confocal laser scanning microscopy and cryo scanning electron microscopy. Bioresour Technol 2010, 101(6):1920-1926.
49. Papagianni M: Quantification of the fractal nature of mycelial aggregation in Aspergillus niger submerged cultures. Microbial Cell Factories 2006, 5(1):5

50. Tucker K, Thomas C: Effect of biomass concentration and morphology on the rheological parameters of Penicillum chrysogenum fermentation broths. Trans Inst Chem Eng 1993, 71:111-117.

51. Hille A, Neu TR, Hempel DC, Horn H: Effective diffusivities and mass fluxes in fungal biopellets. Biotechnol Bioeng 2009, 103(6):1202-1213.

52. McIntyre M, Müller C, Dynesen J, Nielsen J: Metabolic Engineering of the Morphology of Aspergillus. Adv Biochem Eng/Biotechnol 2001, 73:103-128.

53. Wösten HAB, Moukha SM, Sietsma JH, Wessels JGH: Localization of growth and secretion of proteins in Aspergillus niger. J Gen Microbiol 1991 137(1):2017-2023.

54. Wongwicharn A, McNeil B, Harvey L: Effect of Oxygen Enrichment on Morphology, Growth, and Heterologous Protein Production in Chemostat Cultures of Aspergillus niger B1-D. Biotech Bioeng 1999, 65(4):416-424.

55. Amanullah A, Blair R, Nienow AW, Thomas CR: Effects of Agitation Intensity on Mycelial Morphology and Protein Production in Chemostat Cultures of Recombinant Aspergillus oryzae. Biotechnol Bioeng 1999, 62(4):434-446

56. Grimm LH, Kelly S, Völkerding II, Krull R, Hempel DC: Influence of Mechanical Stress and Surface Interaction on the Aggregation of Aspergillus niger Conidia. Biotechnol Bioeng 2005, 92(7):879-888.

57. O'Mahony RJ, Burns ATH, Millam S, Hooley P, Fincham DA: Isotropic growth of spores and salt tolerance in Aspergillus nidulans. Mycological Research 2002, 106(12):1480-1486.

58. Osherov N, May GS: The molecular mechanisms of conidial germination. FEMS Microbiol Lett 2001, 199(2):153-160.

59. Grimm LH, Kelly S, Hengstler J, Göbel A, Krull R, Hempel DC: Kinetic studies on the aggregation of Aspergillus niger conidia. Biotechnol Bioeng 2004, 87(2):213-218.

60. Trinci AP: A kinetic study of the growth of Aspergillus nidulans and other fungi. J Gen Microbiol 1969, 57(1):11-24.

61. Dantigny $P$, Bensoussan M, Vasseur V, Lebrihi A, Buchet C, Ismaili-Alaoui M, Devlieghere F, Roussos S: Standardisation of methods for assessing mould germination: A workshop report. Int J Food Microbiol 2006, 108(2):286-291.

62. Judet D, Bensoussan M, Perrier-Cornet J-M, Dantigny P: Distributions of the growth rate of the germ tubes and germination time of Penicillium chrysogenum conidia depend on water activity. Food Microbiol 2008, 25(7):902-907.

63. Araujo R, Rodrigues AG: Variability of Germinative Potential among Pathogenic Species of Aspergillus. J Clin Microbiol 2004, 42(9):4335-4337.

64. Papagianni M, Mattey M: Morphological development of Aspergillus niger in submerged citric acid fermentation as a function of the spore inoculum level. Application of neural network and cluster analysis for characterization of mycelial morphology. Microbial Cell Factories 2006, 5(1):3.

65. Carlsen M, Spohr AB, Nielsen J, Villadsen J: Morphology and physiology of an alpha-amylase producing strain of Aspergillus oryzae during batch cultivations. Biotechnol Bioeng 1996, 49(3):266-276.

66. Mattern I, van Noort J, van den Berg C, Archer D, Roberts I, van den Hondel C: Isolation and characterization of mutants of Aspergillus niger deficient in extracellular proteases. Mol Gen Genomics 1992, 234:332-336.

67. van Hartingsveldt W, Mattern I, van Zeijl C, Pouwels P, van den Hondel C: Development of a homologous transformation system for Aspergillus niger based on the pyrG gene. Mol Gen Genet 1987, 206:71-75.

68. Withers J, Swift R, Wiebe M, Robson G, Punt P, van den Hondel C, Trinci A: Optimization and stability of glucoamylase production by recombinant strains of Aspergillus niger in chemostat culture. Biotech Bioeng 1998, 4(59):407-418.

69. Huggett A, Nixon D: Use of glucose oxidase, peroxidase, and Odianisidine in determination of blood and urinary glucose. Lancet 1957, 273(6991):368-370.

70. Becker J, Klopprogge C, Schroder H, Wittmann C: Metabolic Engineering of the Tricarboxylic Acid Cycle for Improved Lysine Production by Corynebacterium glutamicum. Appl Environ Microbiol 2009, 75(24):7866-7869. 
71. ImageJ. [http://rsbweb.nih.gov/ij/].

72. Collins TJ: ImageJ for microscopy. BioTechniques 2007, 43(1 Suppl):25-30.

doi:10.1186/1475-2859-10-58

Cite this article as: Wucherpfennig et al:: Morphology engineering -

Osmolality and its effect on Aspergillus niger morphology and productivity. Microbial Cell Factories 2011 10:58,

Submit your next manuscript to BioMed Central and take full advantage of:

- Convenient online submission

- Thorough peer review

- No space constraints or color figure charges

- Immediate publication on acceptance

- Inclusion in PubMed, CAS, Scopus and Google Scholar

- Research which is freely available for redistribution

Submit your manuscript at 